\title{
Implementing a patient decision aid, a process evaluation of a large-scale pre- and post-implementation trial
}

\author{
D. B. Raphael Daniela ${ }^{1,2,3}$ (1) N. S. Russell ${ }^{3}$ E. van Werkhoven ${ }^{4} \cdot$ J. M. Immink ${ }^{5,6}$ - D. P. G. Westhoff ${ }^{7}$. \\ M. C. Stenfert Kroese ${ }^{8} \cdot$ M. R. Stam ${ }^{9} \cdot$ L. M. van Maurik ${ }^{10}$. C. M. J. van Gestel ${ }^{11} \cdot$ T. van der Weijden $^{2}$. L. J. Boersma ${ }^{1}$
}

Received: 2 September 2020 / Accepted: 8 October 2020 / Published online: 24 October 2020

(c) The Author(s) 2020

\begin{abstract}
Purpose Patient decision aids (PtDAs) have been reported to have a positive influence on patients making a health care decision in trials. Nevertheless, post-trial implementation is poor. The aim of this study is to explore patient, clinician, and organizational success factors for implementing a PtDA designed for breast cancer patients, facing a decision on their radiation treatment.

Methods We performed a process evaluation within a multi-center pre- and post-implementation trial. The PtDA was incorporated as much as possible in the logistics of 13 participating centers. Tracking data were collected on PtDA use. Process characteristics were recorded by both clinicians and patients. A logistic regression method was applied to investigate which process characteristics were significantly related to the probability that patients logged in to the PtDA.

Results 189 patients received the PtDA of whom140 (77\%) used the PtDA. If patients received the link via the surgery department they were more likely to use the PtDA (OR 9.77 (1.28-74.51)), compared to patients that received the link via the radiation oncology department. If the report of the multidisciplinary team stated that radiation treatment "had to be discussed with the patient", patients were more likely to use the PtDA (OR 2.29 (1.12-4.71)). Educational level was not related to the probability of PtDA use.

Conclusions We accomplished a high level of PtDA use. Patients were more likely to use the PtDA if they received the link via the surgery department and if "to be discussed with the patient" was written in the multidisciplinary team report.
\end{abstract}

Keywords Patient decision aid $\cdot$ Implementation $\cdot$ Breast irradiation $\cdot$ Shared decision-making

$\begin{array}{ll}\text { Abbreviations } \\ \text { PtDA } & \text { Patient decision aid } \\ \text { MDT } & \text { Multidisciplinary team } \\ \text { RT } & \text { Radiation treatment } \\ \text { SDM } & \text { Shared decision-making } \\ \text { CFIR } & \text { Consolidated framework for implementation } \\ & \begin{array}{l}\text { research } \\ \text { CRF }\end{array} \\ \end{array}$

Work presented at: EACH, Leiden, The Netherlands, September 2019.

\section{J. Boersma}

liesbeth.boersma@maastro.nl

Extended author information available on the last page of the article

\section{Introduction}

Patient decision aids (PtDA) have been found to support the process of shared decision-making (SDM) [1-4]. In a review of 105 randomized clinical trials, Stacey et al. found that PtDAs improve quality of the decision-making process, lower decisional conflict and improve patient-clinician communication, without causing any harm [5, 6]. Despite these positive effects in clinical trials, PtDAs facilitating SDM have not been widely implemented in medical practice [7, 8]. Stacey et al. found a low uptake of PtDAs after trials, with only $21 \%$ of PtDAs being implemented, and another $7 \%$ being part of implementation studies [9].

While research on SDM and the effectiveness of PtDAs has grown rapidly over the last years [10], research on implementation of PtDAs in oncology care lags behind [11]. A lot of effort has been made to explore patient, clinician, and organization-related factors that determine the level of uptake of PtDAs but no hard conclusions can be drawn yet 
[7]. Frequently mentioned barriers include clinicians' attitude toward the use of PtDAs and SDM, e.g., clinicians are less likely to use the PtDA when they lack confidence in the content of the PtDA, or if they believe that the PtDA does not fit their patient population [7, 12]. In addition, clinicians often feel that referring to a PtDA and using the PtDA during consultation might be too time consuming [7, 13-15]. Standardized referral to PtDAs prior to the decision-making consultation has therefore been identified as a facilitator for PtDA use [7]. A review by Elwyn et al. on the implementation of PtDAs added organizational barriers: the PtDA not fitting into the workflow of the clinic and lack of leadership might hinder implementation [7, 9]. This was also found in a review by Scholl et al. who reviewed organizational characteristics as barriers for the implementation of shared decision-making [8]. They pointed out the importance of taking characteristics of health care facilities into account to achieve practice changes. A comparative trial in prostate cancer patients also showed large differences in PtDA uptake with different approaches of PtDA dissemination [16].

We developed an online PtDA for breast cancer patients facing a decision in their radiation treatment (RT) [17]. RT after surgery lowers local recurrence rate but in certain groups of patients, this does not clearly translate into an improved survival rate [18-20]. The trade-off between RT accompanied with a lower local recurrence rate versus the possible side effects is therefore a preference sensitive decision [21].

We performed a multi-center, pre and post-implementation study with a pragmatic approach, adapting the implementation strategy to the logistics of the different centers (BRASA-study) The aim of the current paper is to report on the process evaluation of this study, by describing the level of uptake of the PtDA, and by analyzing whether we can identify patient, clinician, and organizational factors that are related to an increased level of uptake of the PtDA. The effects of the intervention on patient outcomes such as decision conflict will be described separately.

\section{Methods}

We performed a process evaluation of the introduction of a PtDA within the BRASA-study (NCT03375801), a multicenter pre and post-implementation trial in which the intervention was the use of a PtDA. This trial has a pragmatic design to test the uptake and the effect of a PtDA $[17,21]$ in a setting conformed to normal clinical practice [22-24].

\section{Participants}

All 19 radiation oncology centers in the Netherland were invited to participate in the study. One breast cancer radiation oncologist per center was invited through personal contact by e-mail.

Patients were recruited between October 2018 and July 2019. Eligibility criteria for study participation were female breast cancer patient of 18 years or older, with the ability to comprehend Dutch to understand the content of the PtDA and to give informed consent. The PtDA was developed for four sub-groups with a preference-sensitive indication of RT: DCIS group, low risk breast cancer group, thoracic wall irradiation group and boost/no boost group (Table 1). The multidisciplinary team (MDT) of the participating hospitals or the treating clinician determined whether the RT indication had to be discussed with the patient, and thus whether the patient was eligible for participating in the BRASA-study.

\section{Intervention}

\section{Patient decision aid (PtDA)}

The PtDA is an online tool, only available in Dutch on www. beslissamen.nl, for decision-making on breast cancer RT. The PtDA was developed according to the international criteria for PtDA development (IPDAS criteria [3]), as described earlier [17]. In short, the PtDA starts with general information on SDM and an explanation on the PtDA use. The PtDA makes clear that there is a preference-sensitive decision to be made. Subsequently, general information is given on DCIS or breast cancer with links to the website of the national breast cancer association for more information.

Table 1 The four sub-groups for whom the PtDA was developed

Patients with low risk ductal carcinoma in situ (DCIS) after breast conserving surgery deciding on whole/partial breast RT or no RT (DCIS group)

Patients with low risk invasive ductal carcinoma after breast conserving surgery deciding on whole/partial breast RT or no RT (low risk breast cancer group)

Patients with intermediate risk breast cancer after mastectomy deciding on thoracic wall RT or no RT (thoracic wall irradiation group)

Patients with intermediate risk breast cancer after breast conserving surgery deciding on whole breast RT with or without an extra boost dose to the tumor bed (boost / no boost group) 
In addition, general information on the working mechanism and practical aspects of RT is given by written text and by a short animation film. The information of the rest of the PtDA is personalized for the four different sub-groups as mentioned in Table 1, such as information on possible side effects, recurrence rates, and possible survival benefit. We applied textual and graphical risk communication strategies, such as percentages, numeral frequencies, and population diagrams, in combination with clarification of uncertainties in text [17]. The PtDA also includes a section where patients are supported in constructing their treatment preferences and involvement in the SDM process. It is possible for patients to print an overview of their preferences, to bring to the consultation with their clinician. Patients can use the PtDA at home, at their own pace. The PtDA was reviewed by Vromans et al. and scored 83 points out of 100 [25].

\section{Strategies to implement the PtDA}

We developed so called "recipe cards" to enable the clinician to refer patients to the website with a login code. On these "recipe cards", patients could also see which pathway they had to follow, according to their medical situation (Fig. 1). The trial logistics and PtDA use was adapted to the specific logistics and organizational preferences of each participating site. Three different moments in the care path could be distinguished to distribute the "recipe cards" in the participating centers (Fig. 2).

Via the surgery department

1. Eligible patients were identified on the post-operative multidisciplinary team meeting (MDT), and eligibility was captured in the MDT-report. Patients received the "recipe card" via the surgery department at the postoperative consultation. They referred the patient to the radiation oncologist to discuss $\mathrm{RT}$ and gave information about the PtDA and the trial. Patients could use the PtDA at home, prior to their consultation at the RT department.

Via the radiation oncology department

2. Eligible patients were identified on the post-operative MDT, and eligibility was captured in the MDT-report. Trial managers from the RT department sent information about the PtDA and the trial to the patient through regular post, together with the "recipe card". Patients could use the PtDA at home, prior to their consultation at the RT department.

3. Eligible patients were informed about the study once they visited the RT department. Patients received the "recipe card" from the clinician in the RT department during the consultation. They could use the PtDA dur- ing consultation, and after the consultation at home. If necessary, a second consultation was planned.

Individual caregivers could freely choose to adapt their trial logistics for individual patients. For example, if participating centers used option 1 or 2 , but patients accidentally did not receive the recipe card prior the consultation with the RT, they could follow option 3, allowing the radiation oncologist to include eligible patients anyway. In most centers, more than one of the three above7mentioned logistic options were used. Since option 2 was not foreseen when the patient questionnaire was developed, regular post was not included in the answer options on the question from who they had received the PtDA link. Consequently, we only analyzed differences between two strategies: link received via the surgical or the RT department.

\section{Data collection}

We collected data from three sources (Table 2):

1. Tracking data: Clinicians in the participating hospitals recorded the login code of the "recipe" cards given to the patient on the case report form (CRF). When patients logged in to the website, this was automatically registered.

2. Patient questionnaires: Patients were asked to fill in a questionnaire after the consultation in which the decision was made. In this questionnaire, we asked from whom and when the patient had received the recipe card, if they had used the PtDA and if they had used the PtDA, if they perceived it as being useful. In addition, we asked some general questions e.g., on educational level, as defined by the SOI 2016 classification [26].

3 . The including clinician filled in a standardized consultation registration form, part of the CRF. The CRF included questions on birth date, disease and treatment characteristics, consultation length and if there was a note in the multidisciplinary team report stating that "RT had to be discussed with the patient".

\section{Data analysis}

Tracking data were used as a binary outcome. When patients logged in to the PtDA this was automatically registered. Patients were coded to have logged in to the PtDA if a login session was registered, independent of the length and the number of times patients logged in. Patients were coded as not having logged in to the PtDA if the login code was known but no login session was registered by the system. 
Fig. 1 Front and backside of the recipe card

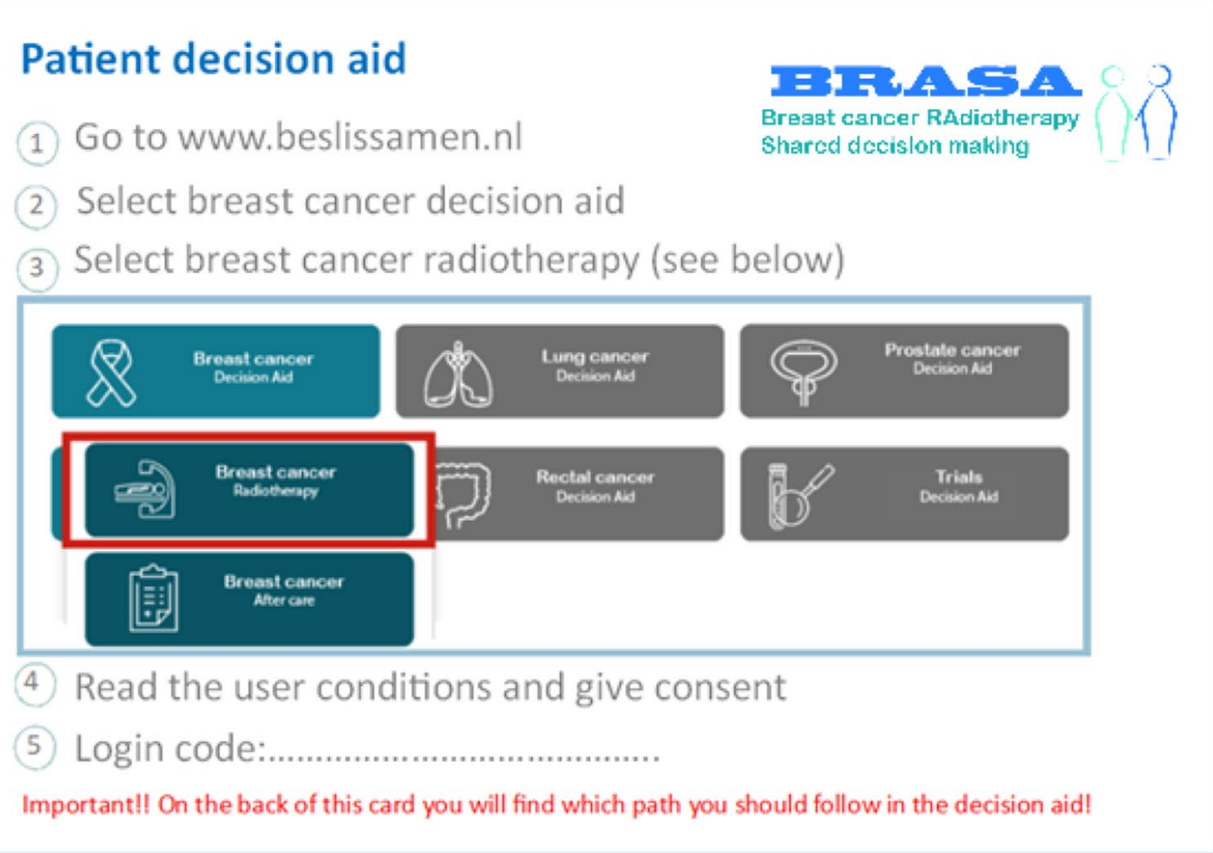

In the decision aid you will be asked to choose 1 out of these 4 paths. Choose the figure that is marked by your clinician.

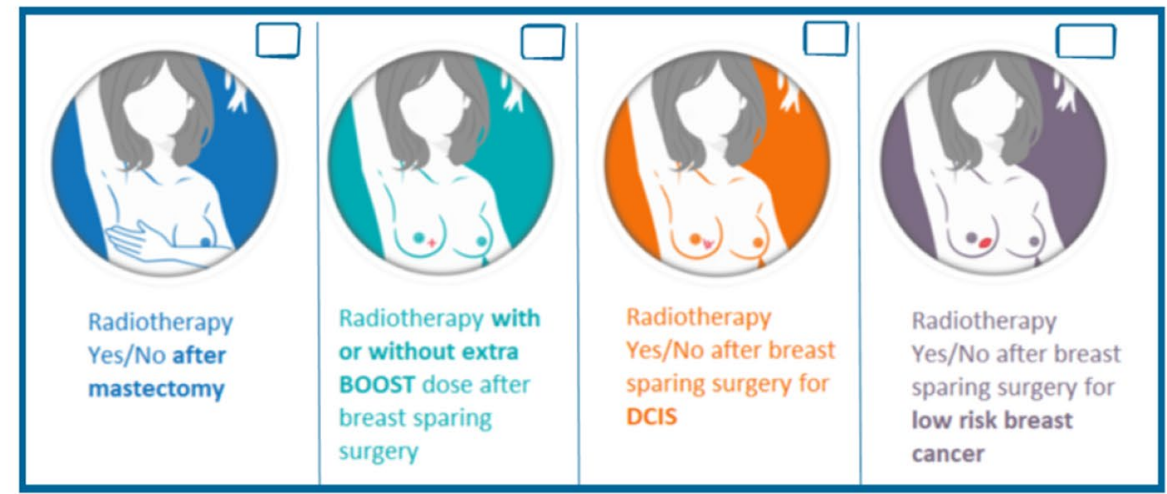

For questions on the decision aid or the BRASA-study:

$\bowtie$ brasa@nki.nl C.020xxxxxxxx
Patients were coded as missing when their login code was unknown.

Descriptive statistics were used to describe patient characteristics and information from the patient questionnaires. The question from whom they had received the link to the PtDA was recoded to three categories: (1) When patients had received the link from the surgeon or the nurse practitioner this was coded as having received the link from the surgery department; (2) Patients who received the link from the radiation oncologist or the physician assistant were coded as having received the link from the radiation department;
(3) The third category was the option "other". Educational level was recoded to low, middle and high as defined by the SOI 2016 classification [26].

Descriptive statistics were used to describe the distribution of patients between the four indications for RT and if it was indicated in the MDT-report that RT "had do be discussed with the patient".

Univariable logistic regression was used to compare patients who had and had not logged in to the PtDA. The independent variables tested included: from whom patients received the PtDA link, educational level, whether SDM was 


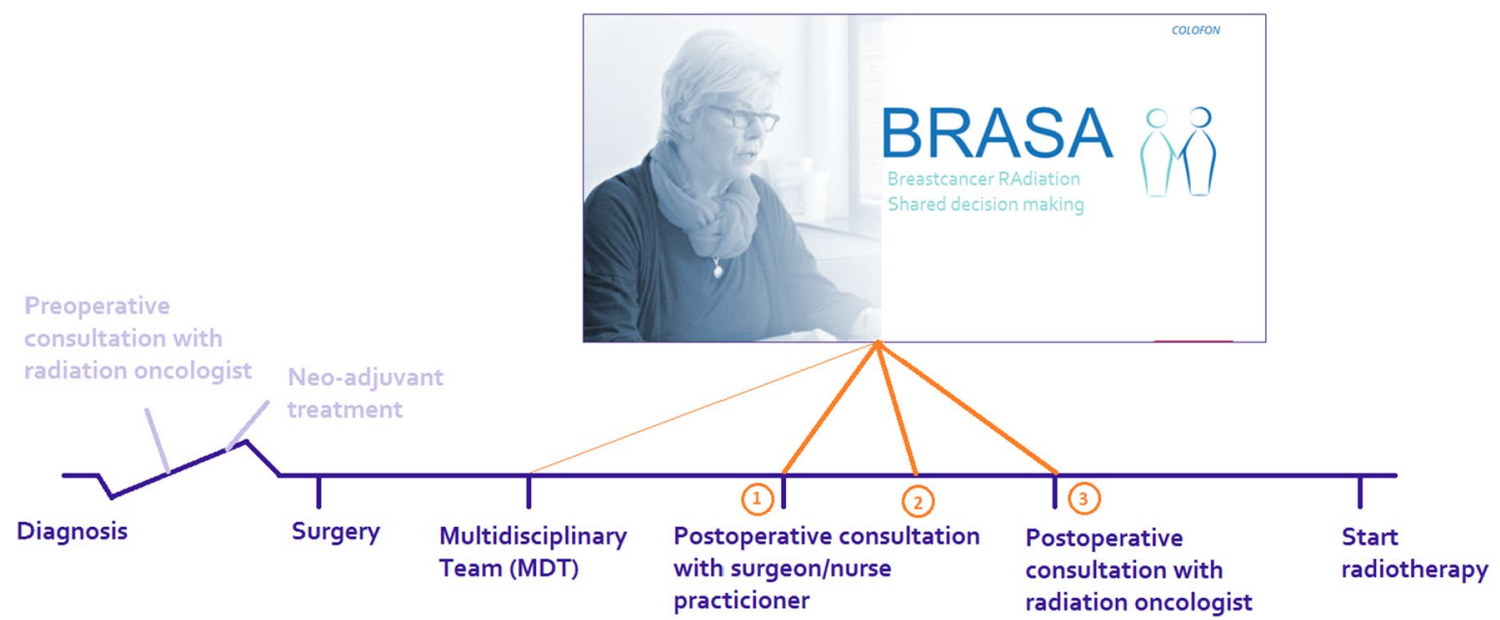

Fig. 2 Possible moments in care path to hand over the recipe card to the patient. 1: Patients received the "recipe card" via the surgery department at the post-operative consultation; 2: patients received the "recipe card" via the radiation oncology department via regular post; and 3: patients received the "recipe card" via the radiation oncology department during the post-operative consultation

Table 2 Overview of the different data to be collected

\section{Log data}

2. Case report form

to be filled in by radiation oncologist

3. Patient questionnaire
Log data was automatically tracked when patients logged in to the PtDA

Did the multidisciplinary board register "to discuss RT with the patient" in the multidisciplinary team report?

O No

O Yes

There is no report of the multidisciplinary team meeting

Can you indicate the consultation length? .... min

From whom did you receive the link to the decision aid?

O Surgeon

O Nurse/Nurse practitioner at surgery department

Radiation oncologist

Nurse/physician assistant at radiation oncology department

$\bigcirc$ Other, being.

Did you consider the decision aid to be useful/did it help in the decision-making process?

O Yes

O Partly

O No

What is your highest education?

Primary school

Lower secondary education

Preparatory vocational education

$O$ Vocational education

Senior general secondary education

$\bigcirc$ Pre-university education

O Higher professional education

$\bigcirc$ University 
indicated in the MDT-report and the indication for RT. We were not able to run a multivariable analysis due to the limited sample size of the categories.

\section{Results}

14 of the 19 RT centers in the Netherlands agreed to participate in the trial of whom thirteen centers included patients. Patient inclusion started as soon as the trial was approved in each individual center, resulting in a spread in first inclusion per center (Fig. 3). There was also a spread for breast cancer patients treated per center, varying between around 1100 new patients per year in the largest center and around 200 patients in the smaller centers. 78 different clinicians included 189 patients. 185 patients filled in their questionnaire, and of 188 patients a case report form was filled in by their radiation oncologist. From eight patients the login code was unknown, such that tracking of their PtDA use was not possible. Full data were available for 181 patients.

\section{Patient characteristics}

The mean age was 60.4 years (SD 11.3), $40 \%$ of the patients were highly educated. The low risk DCIS group was the largest group (33\%), followed by the low risk invasive breast cancer group (31\%) and the boost/no boost group (25\%). Fewer patients deciding on thoracic wall RT were included (11\%) (Table 3). Patients in the low-risk breast cancer group were the oldest group (mean 67.3 (SD 9.1)), whereas the boost/no boost group patients were the youngest (mean 54.7 (SD 11.1)).

\section{Decision aid use and process characteristics}

From the tracking data, we found that $140(77 \%)$ patients logged in to the PtDA, whereas 41 patients did not login to the PtDA. 158 patients reported to have used the PtDA of which 136 were traced by the tracking data (Table 4). Of the patients who used the PtDA, $88 \%$ perceived the PtDA as being (partly) useful. In 114 patients $(65 \%)$ eligibility had been captured in the MDT-report (Table 5). In the univariable analyses, we found that when the surgery department provided the link to the patient, patients were more likely to login to the PtDA, OR 9.77 (95\% CI 1.28-74.51). In addition, when a remark in the MDT-report on the indication for SDM was found, patients were more likely to login to the PtDA, OR 2.29 (95\% CI 1.12-4.71). There was no difference in login frequency between the four different sub-groups/ indication for RT. Educational level did not differ between the group who did and did not login to the PtDA. There was no difference in consultation length between the group who logged in to the PtDA and those who did not (mean $41.9 \mathrm{~min}$ (SD 13.0) versus $40.5 \mathrm{~min}$ (SD 11.8).

\section{Discussion}

The major finding in this pragmatic trial was that we reached a high level of PtDA use: $77 \%$ of the patients (140 out of 181) logged in to the PtDA [15, 27]. In addition, we found that handing out the link via the surgery department, and a remark in the MDT-report, RT is to be discussed with the patient, increased the number of patients logging in to the PtDA.
Fig. 3 Inclusions per participating center and number of patients logging in or not. Number of inclusions per participating centers. Each bar represents one of the participating centers. Participating centers are ordered by starting date of first inclusion

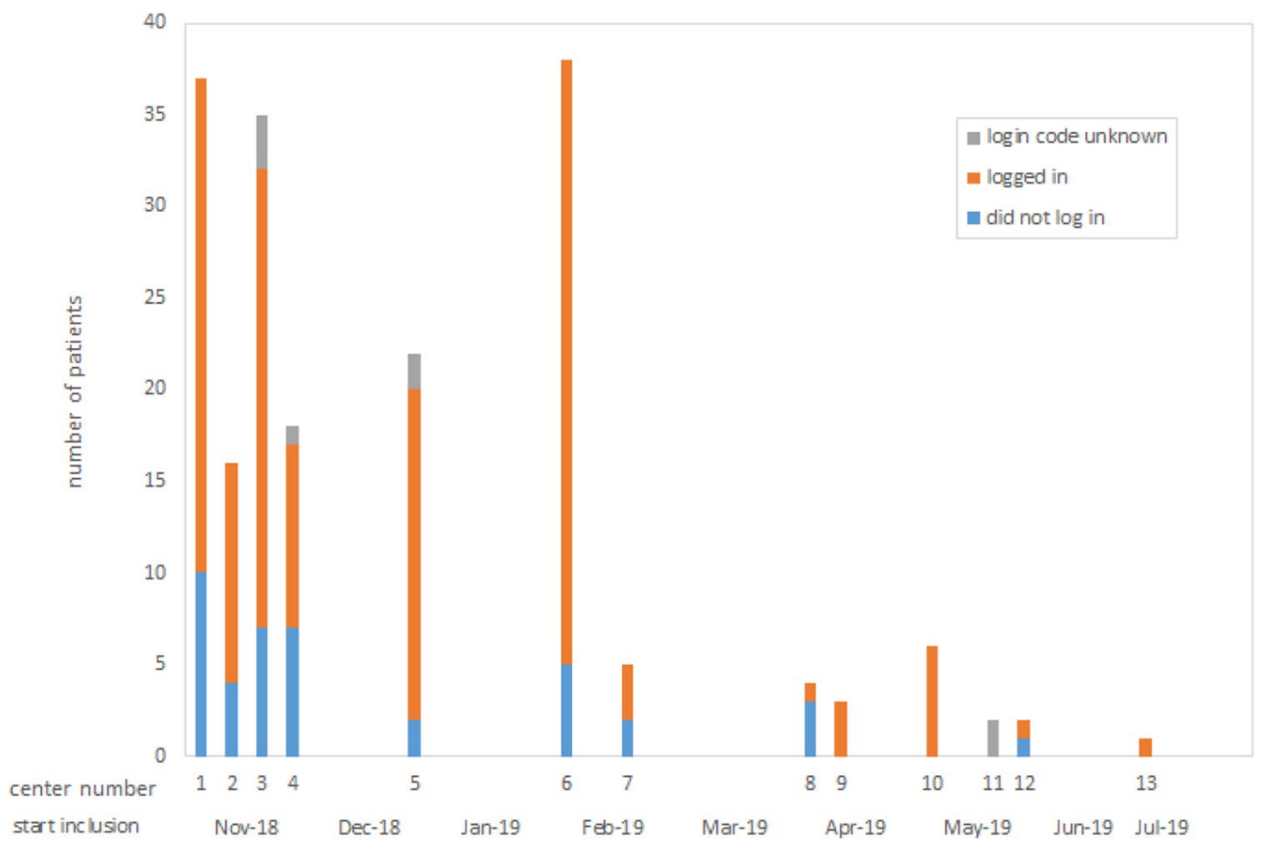


Table 3 Patient characteristics of all 189 included patients

\begin{tabular}{|c|c|}
\hline & Mean (SD) \\
\hline Age in years & $60.4(11.3)$ \\
\hline \multirow[t]{2}{*}{ Consultation length in minutes } & $41.7(13.5)$ \\
\hline & $\begin{array}{l}\text { Total } N=189 \\
N(\%)\end{array}$ \\
\hline \multicolumn{2}{|l|}{ Received Patient decision aid via: } \\
\hline Surgery department & $33(19 \%)$ \\
\hline Radiation oncology department & $135(76 \%)$ \\
\hline Other & $10(6 \%)$ \\
\hline Missing & 11 \\
\hline \multicolumn{2}{|l|}{ Educational level } \\
\hline Low & $50(27 \%)$ \\
\hline Middle & $59(32 \%)$ \\
\hline High & $73(40 \%)$ \\
\hline Missing & 7 \\
\hline \multicolumn{2}{|c|}{ SDM indicated in multidisciplinary team report } \\
\hline Yes & $120(66 \%)$ \\
\hline No & $62(34 \%)$ \\
\hline Missing & 7 \\
\hline \multicolumn{2}{|l|}{ Indication for radiation treatment } \\
\hline DCIS & $62(33 \%)$ \\
\hline Low risk breast cancer & $58(31 \%)$ \\
\hline Boost /no boost & $47(25 \%)$ \\
\hline Thoracic wall irradiation & $21(11 \%)$ \\
\hline \multirow[t]{2}{*}{ Missing } & 1 \\
\hline & $\mathrm{N}=140$ \\
\hline \multicolumn{2}{|l|}{ Perceived decision aid as being useful } \\
\hline Yes & $55(40 \%)$ \\
\hline Partly & $64(47 \%)$ \\
\hline No & $17(13 \%)$ \\
\hline Missing & 4 \\
\hline
\end{tabular}

Table 4 Overview of tracking data and patients answer on the questionnaire on PtDA use

\begin{tabular}{lrrlr}
\hline & \multicolumn{2}{l}{ Tracking data } & Total \\
\cline { 2 - 4 } & Did login & Did not login & Missing & \\
\hline Patient questionnaire & & 16 & 6 & 158 \\
Did use PtDA & 136 & 22 & 2 & 26 \\
Did not use PtDA & 2 & 3 & 0 & 5 \\
Missing & 2 & 41 & 8 & 189 \\
Total & 140 & &
\end{tabular}

We think that the high uptake level was reached because we tackled several known barriers during trial initiation. As described in our previous paper [17], the PtDA was developed by the research team, including radiation oncologists in collaboration with clinicians from different radiotherapy centers in the Netherlands. This might have facilitated confidence in the PtDA by clinicians, which is also supported by the fact that 78 different clinicians included patients. This confidence in the intervention, or feeling of ownership, is also stated as important in the Consolidated Framework For Implementation Research (CFIR) where it is described as "commitment, involvement and accountability of leaders and managers with the implementation" [28]. Furthermore, with the pragmatic trial approach we tackled many other known barriers mentioned in the CFIR, such as logistics and leadership: by adapting the implementation of the PtDA to the logistics of the different centers, it interfered as little as possible with the routine in each center. Leadership was accomplished by having dedicated clinicians as principal investigator in each of the participating centers. In the Netherlands, there is a well-functioning national platform for breast cancer radiotherapy, which has been existing for 20 years. This 
Table 5 Results of the univariable logistic regression analysis in the 181 patients for whom tracking data were available

\begin{tabular}{llllr}
\hline & Did login & Did not login & OR (95\%CI) & Difference \\
\hline N (\%) & $140(77 \%)$ & $41(23 \%)$ & & \\
Mean age in years (SD) & $59.5(11.0)$ & $63.4(11.9)$ & $0.97(-0.01-7.90)$ & 3.9 \\
Consultation length in minutes (SD) & $41.9(13.0)$ & $40.5(11.8)$ & $1.00(-5.98-3.18)$ & -1.4 \\
Received patient decision aid via: & & & & \\
Radiation oncology & $98(75 \%)$ & $33(25 \%)$ & 1 & \\
Surgery & $29(97 \%)$ & $1(3 \%)$ & $9.77(1.28-74.51)$ & \\
Other & $9(90 \%)$ & $1(10 \%)$ & $3.03(0.37-24.83)$ & \\
Missings & 4 & 6 & & \\
Educational level & & & 1 & \\
Low & $34(72 \%)$ & $13(28 \%)$ & $1.43(0.58-3.53)$ & \\
Middle & $45(79 \%)$ & $12(21 \%)$ & $1.52(0.64-3.64)$ & \\
High & $56(80 \%)$ & $14(20 \%)$ & & \\
Missings & 5 & 2 & 1 & \\
Indicated in multidisciplinary team report & & & \\
No & $41(67 \%)$ & $20(33 \%)$ & & \\
Yes & $94(82 \%)$ & $20(18 \%)$ & $2.29(1.12-4.71)$ & \\
Missings & 5 & 1 & $0.52(0.10-2.62)$ & \\
Indication for radiation treatment & & & & \\
Thoracic wall RT & $18(90 \%)$ & $2(10 \%)$ & 1 & \\
DCIS & $47(82 \%)$ & $10(18 \%)$ & & \\
Low risk breast cancer & $43(75 \%)$ & $14(25 \%)$ & $0.34(0.07-1.66)$ & \\
Boost/no boost & $32(70 \%)$ & $14(30 \%)$ & $0.25(0.05-1.25)$ & \\
Missings & 0 & 1 & & \\
\hline
\end{tabular}

mono-disciplinary platform includes at least one breast cancer radiation oncologist from every RT center, resulting in a strong cohesion. A disadvantage is that other breast cancer specialists, such as surgeons and medical oncologists are not represented. We hypothesize that this was overcome by the dedicated radiation oncologists who informed the surgeons of their referring centers about the trial.

We found in our trial that patients receiving the link to the PtDA via the surgery department were more likely to login. It is known that if the patient is given a concrete treatment advice by the surgeon, without explaining the treatment to be preference sensitive, patients might be less open for SDM since they might feel that choosing another treatment than advised by the surgeon goes against his advice [29, 30]. Therefore, when the link to the PtDA is handled via the surgery department, patients were probably more aware that they had a choice. Patients could use the PtDA prior the consultation with the radiation oncologist to be prepared for the consultation and already contemplate on what is important to them [13]. In our study though, we also had a group of patients who received the link to the PtDA via the RT department by regular post, prior the consultation, such that these patients could also use the PtDA for the preparation of the consultation. This might explain the good uptake in the RT group as well. Since we did not register whether the patients received the link per regular post, we cannot draw firm conclusions on which factor is more important: the timing of receiving the link (prior to the consultation with the radiation oncologist), or the department handing out the link (surgery department or RT department).

Capturing eligible patients by the MDT was also found to be an important facilitator. Savelberg et al.: pointed out that if the MDT-report gives an advice, favoring one of the treatment options, it might be harder for clinicians and patients to overrule this advice [30, 31]. It is not surprising that if the MDT-report did not capture the indication for the PtDA, the patient more often got the link via the radiotherapy department, since the surgeon is less involved in the indication for radiotherapy than the radiation oncologist.

The mean age of our trial population is in line with the age at diagnosis of breast cancer patients in the Netherlands [32]. Educational level did, however, differ from the general Dutch population in which, around $33 \%$ is highly educated as opposed to $40 \%$ in our trial population [33]. We found only a slightly better PtDA uptake for younger patients compared to the older patients. This also seems in line with literature which shows that older patients do want to participate in the shared decision-making process but they tend to value more the verbal communication with their clinician [34]. Vulnerable patients are known to be under-presented in health care research, and therefore probably also in this trial [35]. Although this might result in less PtDA use in 
patients with a lower educational level, in our study we did not find any difference in PtDA uptake by educational level. This is in line by the results of Pickles et al. who suggest that educational level does not interfere with the effect of a PtDA found in trial setting [36].

A reassuring finding was that we did not find a difference in consultation length between patients who did and did not login to the PtDA. Since perception of time and the fear for longer consultation are known to be important barriers, we hope our results might help implementation of the PtDA in clinical practice $[37,38]$.

A limitation to our study is that we do not know how many patients were eligible for the study but were not offered the PtDA or refused participation. There was a wide variation in amount of patients included by the different centers; this could only partly be explained by different duration of the inclusion periods, and by the big differences in the size of the different centers. Consequently, this may have resulted in overestimation of the actual PtDA use and validation in our trial.

Another limitation is that, although we found that $88 \%$ of the patients that used the PtDA perceived it as being (partly) useful, we have no further insight in the patients' perspectives on the different logistics of receiving the link to the PtDA. Furthermore, due to technical problems, we do not have more specific tracking data on how long and how often patients logged in to the PtDA. Despite this shortcoming, the fact that we could use log data to monitor patients using the PtDA is a strength in this study, since the log data yield objective results. Objective data on uptake seem more valuable than the self-reporting of uptake as we saw in the results of the patient questionnaires that not all patients who reported to have used the PtDA had actually logged in. Patients might have not understood the question or have given a socially desirable answer when asked on PtDA use. Another strength of this trial is that it interfered as little as possible with routine medical practice. This way we were able to find factors that are related to the level of uptake of the PtDA in regular clinical practice without trial limitations. Our real life study design, with 78 different including clinicians, might facilitate post-trial implementation since Glenn et al. found that a positive personal experience and patient satisfaction motivates clinicians more to use a support tool than scientific evidence [39]. In addition, no adjustments are needed to continue using the PtDA in the participating centers after the trial. In this way, we achieved a good uptake of the PtDA when it was offered to patients. The PtDA is currently freely available and is incorporated in the website of the patient organization as proposed by Reumkens et al. [40].

\section{Conclusion}

We accomplished a high PtDA uptake. This may be explained by the pragmatic trial design and apparent leadership in an existing network of the involved clinicians. We found that logistics facilitating the PtDA being offered via the surgery department, prior to the consultation with the radiation oncologist and a note in the MDT-report that the PtDA should be offered, resulted in high PtDA uptake.

Acknowledgements This study is funded by the Dutch Cancer Society, Alpe d'HuZes (Grant No. MAC2014-7024). We would like to thank all patients for participating in the trial. We would also like to thank all principal investigators, trial managers and including clinicians in the participating Centers: Maastro, Antoni van Leeuwenhoek, Reinier de Graaf Hospital, Leiden University Medical Center, Radboud University Medical Center, Radiotherapy Group, Amsterdam University Medical Centers, University Medical Center Utrecht, University Medical Center Groningen, Erasmus Medical Center Cancer Institute, Haga Hospital, Haaglanden Medical Center, Southwest Radiotherapy Institute, Catharina Hospital and, Radiotherapy Institute Friesland.

\section{Funding}

Data availability All data were anonymized by coding personal identifiers.

\section{Compliance with ethical standards}

Conflict of interest All authors declare that they have no conflict of interest.

Research involving human and/or animal participants All procedures performed in studies involving human participants were in accordance with the ethical standards of the institutional and/or national research committee and with the 1964 Helsinki declaration and its later amendments or comparable ethical standards. The study was approved by the Institutional Review Board of the Netherlands Cancer Institute and Maastro and was registered at clinical.trials.gov (NCT02934126).

Informed consent Informed consent was obtained from all individual participants included in the study.

Open Access This article is licensed under a Creative Commons Attribution 4.0 International License, which permits use, sharing, adaptation, distribution and reproduction in any medium or format, as long as you give appropriate credit to the original author(s) and the source, provide a link to the Creative Commons licence, and indicate if changes were made. The images or other third party material in this article are included in the article's Creative Commons licence, unless indicated otherwise in a credit line to the material. If material is not included in the article's Creative Commons licence and your intended use is not permitted by statutory regulation or exceeds the permitted use, you will need to obtain permission directly from the copyright holder. To view a copy of this licence, visit http://creativecommons.org/licenses/by/4.0/. 


\section{References}

1. Coulter A, Collins A (2011) Making shared decision-making a reality: no decision about me, without me. King's Fund, London

2. Elwyn G, Frosch DL, Kobrin S (2016) Implementing shared decision-making: consider all the consequences. Implement Sci IS 11:114. https://doi.org/10.1186/s13012-016-0480-9

3. Elwyn G, O'Connor A, Stacey D, Volk R, Edwards A, Coulter A, Thomson R, Barratt A, Barry M, Bernstein S, Butow P, Clarke A, Entwistle V, Feldman-Stewart D, Holmes-Rovner M, Llewellyn-Thomas H, Moumjid N, Mulley A, Ruland C, Sepucha K, Sykes A, Whelan T (2006) Developing a quality criteria framework for patient decision aids: online international Delphi consensus process. BMJ (Clin Res Ed) 333(7565):417. https://doi.org/10.1136/bmj.38926.629329.AE

4. Coulter A, Stilwell D, Kryworuchko J, Mullen PD, Ng CJ, van der Weijden T (2013) A systematic development process for patient decision aids. BMC Med Inform Decis Mak 13(Suppl 2):S2. https ://doi.org/10.1186/1472-6947-13-s2-s2

5. Stacey D, Legare F, Lewis K, Barry MJ, Bennett CL, Eden KB, Holmes-Rovner M, Llewellyn-Thomas H, Lyddiatt A, Thomson R, Trevena L (2017) Decision aids for people facing health treatment or screening decisions. Cochrane Database Syst Rev 4:Cd001431. https://doi.org/10.1002/14651858.CD001431.pub5

6. McAlpine K, Lewis KB, Trevena LJ, Stacey D (2018) What is the effectiveness of patient decision aids for cancer-related decisions? A systematic review subanalysis. JCO Clin Cancer Inform 2:1-13. https://doi.org/10.1200/cci.17.00148

7. Elwyn G, Scholl I, Tietbohl C, Mann M, Edwards AG, Clay C, Legare F, van der Weijden T, Lewis CL, Wexler RM, Frosch DL (2013) "Many miles to go ...": a systematic review of the implementation of patient decision support interventions into routine clinical practice. BMC Med Inform Decis Mak 13(Suppl 2):S14. https://doi.org/10.1186/1472-6947-13-s2-s14

8. Scholl I, LaRussa A, Hahlweg P, Kobrin S, Elwyn G (2018) Organizational- and system-level characteristics that influence implementation of shared decision-making and strategies to address them - a scoping review. Implement Sci IS 13(1):40. https ://doi.org/10.1186/s13012-018-0731-z

9. Stacey D, Suwalska V, Boland L, Lewis KB, Presseau J, Thomson R (2019) Are patient decision aids used in clinical practice after rigorous Evaluation? A survey of trial authors. Med Decis Mak Int J Soc Med Decis Mak 39(7):805-815. https://doi. org/10.1177/0272989x19868193

10. Lu C, Li X, Yang K (2019) Trends in shared decision-making studies from 2009 to 2018: a bibliometric analysis. Front Public Health 7:384. https://doi.org/10.3389/fpubh.2019.00384

11. Herrmann A, Mansfield E, Hall AE, Sanson-Fisher R, Zdenkowski N (2016) Wilfully out of sight? A literature review on the effectiveness of cancer-related decision aids and implementation strategies. BMC Med Inform Decis Mak 16:36. https://doi.org/10.1186/ s12911-016-0273-8

12. Feibelmann S, Yang TS, Uzogara EE, Sepucha K (2011) What does it take to have sustained use of decision aids? A programme evaluation for the Breast Cancer Initiative. Health Expect Int J Pub Particip Health Care Health Policy 14(Suppl 1):85-95. https ://doi.org/10.1111/j.1369-7625.2010.00640.x

13. Joseph-Williams N, Lloyd A, Edwards A, Stobbart L, Tomson D, Macphail S, Dodd C, Brain K, Elwyn G, Thomson R (2017) Implementing shared decision making in the NHS: lessons from the MAGIC programme. BMJ (Clin Res Ed) 357:j1744. https:// doi.org/10.1136/bmj.j1744

14. Légaré F, Thompson-Leduc PJ (2014) Twelve myths about shared decision making. Patient Educ Couns 96(3):281-286

15. Brackett CD, Kearing S (2015) Use of a web-based survey to facilitate shared decision making for patients eligible for cancer screening. Patient 8(2):171-177. https://doi.org/10.1007/s4027 1-014-0079-7

16. Stacey D, Taljaard M, Breau RH, Baba N, Blackmore T, Boland L, Carley M, Wu RC, Smylie J, Legare F (2018) A patient decision aid for men with localized prostate cancer: a comparative case study of natural implementation approaches. Cancer Nurs. https ://doi.org/10.1097/ncc.0000000000000651

17. Raphael DB, Russell NS, Immink JM, Westhoff PG, Stenfert Kroese MC, Stam MR, van Maurik LM, van den Bongard H, Maduro JH, Sattler MGA, van der Weijden T, Boersma LJ (2020) Risk communication in a patient decision aid for radiotherapy in breast cancer: how to deal with uncertainty? Breast (Edinburgh, Scotland) 51:105-113. https://doi.org/10.1016/j.breast.2020.04.001

18. Donker M, Litiere S, Werutsky G, Julien JP, Fentiman IS, Agresti R, Rouanet P, de Lara CT, Bartelink H, Duez N, Rutgers EJ, Bijker N (2013) Breast-conserving treatment with or without radiotherapy in ductal carcinoma In Situ: 15-year recurrence rates and outcome after a recurrence, from the EORTC 10853 randomized phase III trial. J Clin Oncol Off J Am Soc Clin Oncol 31(32):4054-4059. https://doi.org/10.1200/jco.2013.49.5077

19. Bagenal J, Roche N, Ross G, Kirby A, Dodwell D (2018) Should patients with ductal carcinoma in situ be treated with adjuvant whole breast radiotherapy after breast conservation surgery? BMJ (Clin Res Ed) 361:k1410. https://doi.org/10.1136/bmj.k1410

20. Recht A, Comen EA, Fine RE, Fleming GF, Hardenbergh PH, Ho AY, Hudis CA, Hwang ES, Kirshner JJ, Morrow M, Salerno KE, Sledge GW Jr, Solin LJ, Spears PA, Whelan TJ, Somerfield MR, Edge SB (2016) Postmastectomy radiotherapy: an American Society of clinical oncology, American Society for radiation oncology, and Society of surgical oncology focused guideline update. Pract Radiat Oncol 6(6):e219-e234. https://doi.org/10.1016/j.prro.2016.08.009

21. Raphael DB, Ter Stege JA, Russell NS, Boersma LJ, van der Weijden T (2019) What do patients and health care professionals view as important attributes in radiotherapy decisions? Input for a breast cancer patient decision aid. Breast (Edinburgh, Scotland) 49:149-156. https://doi.org/10.1016/j.breast.2019.11.005

22. Merali Z, Wilson JR (2017) Explanatory versus pragmatic trials: an essential concept in study design and interpretation. Clin Spine Surg 30(9):404-406. https://doi.org/10.1097/bsd.00000 00000000588

23. Ford I, Norrie J (2016) Pragmatic Trials. New Engl J Med 375(5):454-463. https://doi.org/10.1056/NEJMra1510059

24. Thorpe KE, Zwarenstein M, Oxman AD, Treweek S, Furberg CD, Altman DG, Tunis S, Bergel E, Harvey I, Magid DJ, Chalkidou $\mathrm{K}$ (2009) A pragmatic-explanatory continuum indicator summary (PRECIS): a tool to help trial designers. CMAJ Can Med Assoc J $=\mathrm{J}$ de l'Assoc Med Can 180(10):E47-57. https://doi.org/10.1503/ cmaj.090523

25. Vromans R, Tenfelde K, Pauws S, van Eenbergen M, MaresEngelberts I, Velikova G, van de Poll-Franse L, Krahmer E (2019) Assessing the quality and communicative aspects of patient decision aids for early-stage breast cancer treatment: a systematic review. Breast Cancer Res Treat 178(1):1-15. https:// doi.org/10.1007/s10549-019-05351-4

26. https://www.cbs.nl/nl-nl/onze-diensten/methoden/classificaties/ onderwijs-en-beroepen/standaard-onderwijsindeling--soi--/stand aard-onderwijsindeling-2016. Accessed on 12 May 2020

27. Belkora JK, Volz S, Teng AE, Moore DH, Loth MK, Sepucha KR (2012) Impact of decision aids in a sustained implementation at a breast care center. Patient Educ Couns 86(2):195-204. https:// doi.org/10.1016/j.pec.2011.05.011

28. Damschroder LJ, Aron DC, Keith RE, Kirsh SR, Alexander JA, Lowery JC (2009) Fostering implementation of health services research findings into practice: a consolidated framework for advancing implementation science. Implement Sci IS 4:50. https ://doi.org/10.1186/1748-5908-4-50 
29. Joseph-Williams N, Edwards A, Elwyn G (2014) Power imbalance prevents shared decision making. BMJ (Clin Res Ed) 348:g3178. https://doi.org/10.1136/bmj.g3178

30. Joseph-Williams N, Elwyn G, Edwards A (2014) Knowledge is not power for patients: a systematic review and thematic synthesis of patient-reported barriers and facilitators to shared decision making. Patient Educ Couns 94(3):291-309. https://doi.org/10.1016/j. pec.2013.10.031

31. Savelberg W, Boersma LJ, Smidt M, Goossens MFJ, Hermanns $\mathrm{R}$, van der Weijden T (2019) Does lack of deeper understanding of shared decision making explains the suboptimal performance on crucial parts of it? An example from breast cancer care. Eur J Oncol Nurs Off J Eur Oncol Nurs Soc 38:92-97. https://doi. org/10.1016/j.ejon.2018.12.004

32. https://www.rivm.nl/bevolkingsonderzoek-borstkanker-voor-profe ssionals/feiten-en-cijfers. Accessed 21 Jan 2020

33. https://www.onderwijsincijfers.nl/kengetallen/internationaal/oplei dingsniveau-bevolking. Accessed 23 June 2020

34. Burton M, Collins KA, Lifford KJ, Brain K, Wyld L, Caldon L, Gath J, Revell D, Reed MW (2015) The information and decision support needs of older women ( $>75 \mathrm{yrs}$ ) facing treatment choices for breast cancer: a qualitative study. Psycho-Oncol 24(8):878884. https://doi.org/10.1002/pon.3735

35. Dugas M, Trottier ME, Chipenda Dansokho S, Vaisson G, Provencher T, Colquhoun H, Dogba MJ, Dupere S, Fagerlin A, Giguere AM, Haslett L, Hoffman AS, Ivers NM, Legare F, Legare J, Levin CA, Menear M, Renaud JS, Stacey D, Volk RJ, Witteman HO (2017) Involving members of vulnerable populations in the development of patient decision aids: a mixed methods sequential explanatory study. BMC Med Inform Decis Mak 17(1):12. https ://doi.org/10.1186/s12911-016-0399-8

36. Pickles K, Kazda L, Barratt A, McGeechan K, Hersch J, McCaffery K (2020) Evaluating two decision aids for Australian men supporting informed decisions about prostate cancer screening: a randomised controlled trial. PLoS ONE 15(1):e0227304. https://doi.org/10.1371/journal.pone.0227304

37. Silvia KA, Ozanne EM, Sepucha KR (2008) Implementing breast cancer decision aids in community sites: barriers and resources. Health Expect Int J Pub Participat Health Care Health Policy 11(1):46-53. https://doi.org/10.1111/j.1369-7625.2007.00477.x

38. Pieterse AH, Stiggelbout AM, Montori VM (2019) Shared decision making and the importance of time. JAMA 322(1):25-26. https://doi.org/10.1001/jama.2019.3785

39. Glenn A, Urquhart R (2019) Adopting patient-centred tools in cancer care: role of evidence and other factors. Curr Oncol (Toronto, Ont) 26(1):19-27. https://doi.org/10.3747/co.26.4271

40. Reumkens K, de Die-Smulders CEM, van Osch L (2019) Exploring the preferences of involved health professionals regarding the implementation of an online decision aid to support couples during reproductive decision-making in hereditary cancer: a mixed methods approach. Fam Cancer 18(2):285-291. https://doi. org/10.1007/s10689-019-00119-7

Publisher's Note Springer Nature remains neutral with regard to jurisdictional claims in published maps and institutional affiliations.

\section{Affiliations}

\section{B. Raphael Daniela ${ }^{1,2,3}$ - N. S. Russell ${ }^{3}$ - E. van Werkhoven ${ }^{4} \cdot$ J. M. Immink ${ }^{5,6}$ - D. P. G. Westhoff ${ }^{7}$. M. C. Stenfert Kroese ${ }^{8} \cdot$ M. R. Stam ${ }^{9} \cdot$ L. M. van Maurik ${ }^{10}$. C. M. J. van Gestel ${ }^{11} \cdot$ T. van der Weijden $^{2} \cdot$ L. J. Boersma ${ }^{1}$}

D. B. Raphael Daniela

d.raphael@nki.nl

N. S. Russell

n.russell@nki.nl

E. van Werkhoven

e.v.werkhoven@nki.nl

J. M. Immink

M.Immink@rdgg.nl

D. P. G. Westhoff

Paulien.Westhoff@radboudumc.nl

M. C. Stenfert Kroese

mcstkroese@gmail.com

M. R. Stam

M.Stam@radiotherapiegroep.nl

L. M. van Maurik

1.m.vanmaurik@amc.uva.nl

C. M. J. van Gestel

k.vangestel@zrti.nl

T. van der Weijden

trudy.vanderweijden@maastrichtuniversity.nl

1 Department of Radiation Oncology (Maastro), GROW

School for Oncology and Developmental Biology,

Maastricht University Medical Centre+, Dr. Tanslaan 12,

6229 ET Maastricht, The Netherlands
2 Department of Family Medicine, CAPHRI School for Public Health and Primary Care, Maastricht University, Maastricht, The Netherlands

3 Department of Radiotherapy, Netherlands Cancer Institute, Antoni Van Leeuwenhoek, Amsterdam, The Netherlands

4 Department of Biometrics, Netherlands Cancer Institute, Antoni Van Leeuwenhoek, Amsterdam, The Netherlands

5 Department of Radiation Oncology, Reinier de Graaf Hospital, Delft, The Netherlands

6 Department of Radiation Oncology, Leiden University Medical Center, Leiden, The Netherlands

7 Department of Radiation Oncology, Radboud University Medical Center, Nijmegen, The Netherlands

8 Radiotherapy Group, Deventer, The Netherlands

9 Radiotherapy Group, Arnhem, The Netherlands

10 Department of Radiation Oncology, Amsterdam University Medical Centers, Amsterdam, The Netherlands

11 Southwest Radiotherapy Institute, Roosendaal, The Netherlands 